\title{
MEMÓRIA DISCURSIVA E IDEOLOGIA: ANÁLISE DAS PROPAGANDAS DOS GRANDES EVENTOS ESPORTIVOS DO BRASIL CONTEMPORÂNEO
}

\section{DISCOURSIVE MEMORY AND IDEOLOGY: ANALYSIS OF MAJOR SPORTS EVENTS PROPAGANDA REALIZED IN BRAZIL}

\author{
Anderson Carvalho Pereira \\ Departamento de Ciências Humanas, Educação e Linguagem da \\ Universidade Estadual do Sudoeste da Bahia
}

\begin{abstract}
RESUMO: O artigo investiga modos pelos quais peças publicitárias de grandes eventos esportivos realizados no Brasil (Copa do Mundo de Futebol e Olimpíadas) sustentam mecanismos discursivos voltados ao jogo entre a memória e a ideologia. Para isto, mobiliza conceitos da Análise de Discurso francesa, a saber: memória discursiva e ideologia. Metodologicamente, o estudo filia-se ao paradigma indiciário de análise, cuja interpretação permite reformular hipóteses iniciais. Por fim, aprofunda uma discussão sobre o alcance do determinante político no discurso voltado ao recrutamento e à convocatória unívoca de toda a população a participar destes eventos.
\end{abstract}

Palavras-chave: propaganda; ideologia; memória discursiva.

ABSTRACT: This paper aims at investigating discursive strategies across some information divulgated about the major sports events announced in Brazil (World Cup and Olympic Games) extracted from publicity materials of propaganda. We demonstrated strong evidence forms of political propaganda based on concept of "discourse" and "slips statements" understood by French discourse analysis, based on concepts such as ideology, memory and discourse. Methodologically, this research base on an epistemological model (clues paradigm), that valorizes the alterity between subject and object by reformulation hypothesis. Therefore, there is a relationship between the semantic ideological stability and the discursive memory demonstrated in these propagandas. Keywords: propaganda; ideology; discursive memory.

\section{INTRODUÇÃO}

Há um encadeamento semântico nas propagandas voltadas à Copa do Mundo de Futebol de 2014 e aos Jogos Olímpicos de 2016 no Brasil, cujos efeitos ideológicos têm base em seus determinantes políticos. Deste modo, nosso objetivo neste artigo é investigar em quais efeitos de sentido este determinante político se sustenta. Par isto, acreditamos que a Análise de Discurso de tradição francesa (doravante, AD) oferece um caminho, ao propor a relação entre ideologia e memória discursiva.

$\mathrm{Na}$ grande mídia, em se tratando dos eventos esportivos mais aclamados do período recente da História do Brasil (A Copa do Mundo de Futebol, de 2014 e as Olimpíadas, de 2016) aparecem anúncios que afirmam se tratar de eventos totais, ou 
seja, que incluem todos. Há deste modo um apagamento da polêmica, da discussão e da discordância em suas realizações. O efeito de "somos um só" tal como tem circulado no slogan da rede Globo de televisão é uma materialização deste apagamento, que pode ser entendido como um efeito de naturalização ideológica.

A partir do estranhamento dessa evidência ideológica veiculada em propagandas sobre ambos os eventos esportivos, este artigo mostra a análise de enunciados marcados por imagens e textos, que faz parte de uma discussão sobre o determinante político no discurso.

Temos do ponto de vista da grande mídia dois espetáculos, em que as imagens exercem papel fundamental. Para trilhar esta investigação, mobilizamos principalmente os conceitos de memória discursiva e ideologia da $A D$, porque oferecem subsídios para a discussão dos elementos discursivos implícitos em questão. Após esses caminhos introdutórios, mostramos a análise de peças publicitárias que tem circulado antes e durante a realização desses eventos com o intuito de persuadir a população acerca da necessidade de sua realização. Seguem a apresentação dos conceitos teóricos e a análise do corpus. Trata-se de um corpus formado por propagandas dos dois eventos esportivos acima mencionados, na forma de slogans, textos publicitários e imagens.

Nossa hipótese principal é a de que a memória estabelece um regime de paráfrases (PECHEUX, 1999) e de legibilidade (PECHEUX, 1997), portanto, uma possibilidade de leitura ao interlocutor, em que à textualização (ORLANDI, 2001) em questão, é conferido um encadeamento de evidências ideológicas que não deixa lacunas para rupturas, conferindo uma linearidade eficaz ao convencimento do público-alvo; no caso, trata-se de analisar especificamente, o convencimento da participação dos brasileiros nesses eventos, como voluntários de sua organização e execução. Par isto é fundamental a apresentação dos conceitos de memória discursiva e ideologia, baseados nos pressupostos da AD.

\section{MEMÓRIA DISCURSIVA E IDEOLOGIA PARA A ANÁLISE DE DISCURSO FRANCESA}

Em um primeiro contato com a materialidade do corpus, chama a atenção, a veiculação de expressões como "todos estão convocados". Nosso caminho de investigação, ligado à hipótese inicial é de se tratar de um efeito ideológico eficaz, 
baseado no imaginário de unidade. É este um dos efeitos da ideologia sustentado por meio de uma base material. Em AD, foi Pêcheux quem primeiro tentou articular "a noção de "formação discursiva" à análise das formas materiais da ideologia tais como elas se manifestam nos discursos" (COURTINE, 2013, p. 20).

Em Pêcheux (1993) vemos o marco da teorização sobre esta convergência entre forma material da ideologia e a ilusória centralidade do sujeito em meio às formações discursivas. $\mathrm{O}$ autor percorre a Lógica e a Linguística para tratar do efeito de encaixe e da articulação (pré-construído), que considera insatisfatórios para "tratar da simulação dos conhecimentos científicos no desconhecimento ideológico" (PECHEUX, 1993, p. 124). A partir disto, propõe uma teoria discursiva "da relação do sujeito com aquilo que o representa; portanto, uma teoria da identificação e da eficácia material do imaginário (idem, p. 125)".

A partir das palavras do autor, podemos dizer que neste tom de verdade e evidência marcante do imaginário reside:

O absurdo da evidencia "sou eu" e uma injunção com aspecto policial mascara identificação do sujeito no "estranhamente familiar"; mistura esta "de absurdo e de evidência, e esse retorno do estranho no familiar, já foram encontrados por nós a propósito da noção de pré-construído" (PÊCHEUX, 1993, p.155).

Defendemos que em meio a essa base material há um domínio de memória da propaganda dos eventos esportivos que gira em torno da convocatória de massa. Neste domínio de memória (PÊCHEUX, 1999), há vários dizeres em funcionamento disfarçados por meio das quais se restringe e/ou se camuflam possibilidades do sujeito emergir como intérprete na descontinuidade dos enunciados e a dialética entre "estranho" e "familiar".

Esta descontinuidade marca ressignificações não tão autônomas e anônimas e que funcionam a partir de uma enunciação não coincidente consigo mesma, marcada pelo não dito e pelo implícito, posto que lugar do Outro (cf. AUTHIER-REVUZ, 1998).

A este respeito vale lembrar Achard (1999, p. 13) quando afirma:

Do ponto de vista discursivo, o implícito trabalha então sobre a base de um imaginário que o representa como memorizado, enquanto cada discurso, ao pressupô-lo, vai fazer apelo a sua (re)construção, sob a restrição "no vazio" de que eles respeitem as formas que permitam sua inserção por paráfrase. Mas jamais podemos provar ou supor que esse implícito (re)construído tenha existido em algum lugar como discurso autônomo.

Analisar o implícito e suas reconstruções parafrásticas é mexer com o campo da tensão, da repetição e da inscrição de uma possibilidade de leitura da memória discursiva, eu organiza um regime de legibilidade dos enunciados nela dispostos (PÊCHEUX, 1999) e um efeito de textualização (ORLANDI, 2001), de perceber um lugar "já lá", em função de 
uma estabilidade semântica dada pela ideologia. É com estes conceitos que vamos estabelecer diálogos na análise.

A ideologia em Pêcheux (1993) decorre principalmente da releitura feita por este autor dos méritos da obra althusseriana, a saber: a evidência de que o sujeito "é" e de que uma palavra designa uma coisa (efeito ideológico elementar); a interpelação da ideologia por meio da particularidade em que o alcance superestrutural da ideologia repercute no infraestrutural (evidência de "sou eu"); o paradoxo que chama o sujeito à existência, não porque existe "A ideologia", mas pelo paradoxo que aglutina o modo desta designar o que o sujeito é como condição para tentar se deslocar de sua interpelação. Em suma, Pêcheux (1993) retoma esses méritos e explica que Sujeito e sentido se constituem entre si de modo relacional e contraditório e não de modo marginal a uma suposta constituição tácita d'A ideologia. Ele completa: "o paradoxo é, precisamente, que a interpretação tem, por assim dizer, um efeito retroativo que faz com que todo indivíduo seja "sempre-jásujeito" (PÊCHEUX, 1993, p.155)".

A evidência de que "sou eu" tal que o sujeito identifique em bases materiais um "estranhamente familiar" (PÊCHEUX, 1993, p. 155) resulta do encontro com a memória discursiva, em que residem efeitos de encaixe de dizeres em dizeres outros, de modo que os implícitos estabeleçam regimes de repetição, contradição e recorrência entre si. Disto decorre o efeito de textualização, o efeito de "reconhecer" algo "já dito" em um regime plural e heterogêneo de enunciados.

\section{FORMAÇÃO DO CORPUS DE ANÁLISE}

Do ponto de vista do corpus de análise não podemos deixar de pontuar o fato de que trabalhamos com uma confluência e uma diferença instalada na base semiótica aqui analisada: imagem e texto.

Em uma perspectiva discursiva, Courtine (2013) não aborda a propaganda como gênero textual e aponta que a análise das imagens de peças publicitárias torna-se importante porque servem como estratégia política; é por meio delas que o domínio privado é invadido pela dimensão pública do cotidiano. Este autor retoma as contribuições de Ginzburg (1989) acerca do paradigma indiciário e propõe tratar as imagens como indícios, pistas. 
Isto porque Ginzburg (1989) é o propositor deste paradigma interpretativo alternativo à ciência galileana. Ele aponta que um modelo de tratamento da dispersão de pistas, indícios, sinais, parte da natureza do homem caçador repercutiu numa reconfiguração das ciências ao fim do século XIX, especificamente no plano das Ciências Humanas e Sociais.

Reside nesta reconfiguração um embate com o caráter preditivo do modelo galileano, em meio ao qual se enquadrou a busca por pistas enquadradas em padrões estético-visuais baseadas em biótipos sociais, como feito pela Antropologia Criminal de Lombroso, Becharia e Tarde; e, de outro lado, a interpretação dos indícios numa aliança com disciplinas de valor venatório (marcado pela retroação da análise das pistas, voltadas a uma memória histórica) de que fazem parte a Psicanálise, algumas posturas artísticoliterárias dentre as quais ele destaca Morelli e Conan Doyle (GINZBURG, 1989).

A este respeito Courtine (2013, p. 44) continua a tratar do valor a interpretação de imagens remetendo-as ao paradigma do indício. Em suas palavras:

Como articular estas imagens umas com as outras, como reconstituir estes vínculos que dão seu sentido aos ícones de uma cultura para os indivíduos que compartilham de sua memória? Pelo ajustamento, pela deteç̧ão no material significante da imagem, pelos indícios, pelos rastros, que outras imagens ali depositaram, e pela reconstrução, a partir destes rastros, da genealogia das imagens em nossa cultura.

Ao caminhar por este campo teórico, que se preocupa em articular a base semiótica da imagem com as discussões sobre memória discursiva e o domínio político da evidência ideológica veiculada pela propaganda, mostraremos pontos possíveis de interpretação do corpus lingüístico-discursivo formado por 4 (quatro) peças publicitárias utilizadas na divulgação dos evento esportivos. Este material foi extraído de sites, que tem por objetivo divulgar esses eventos para um público notadamente formado por turistas, principalmente, estrangeiros. Trata-se de um vasto arquivo veiculado na web em forma de imagens e textos, em que se veiculam imagens estereotipadas dos locais dos eventos, ao mesmo tempo em que se dirigem aos brasileiros, que, em tese, devem ajudar como voluntários para a boa organização e realização desses eventos. Analisamos especificamente as peças publicitárias voltadas ao recrutamento de brasileiros voluntários.

Esta materialidade foi organizada e dividida em SDRs (sequências discursivas de referência) em que o respectivo texto descritivo de uma imagem nos três primeiros casos é considerado uma sequência discursiva (SDs; cf. SERRANI, 1997). Temos um diálogo entre SDRs e SDs em que os domínios de memória sustentam efeitos ideológicos cujo 
alcance é da ordem do político. Somente no último caso, foi analisado somente o texto, pois a peça publicitária (como podem ser vistas, ao acessar o link correspondente) privilegiava um texto escrito e não apresentava imagem.

\section{ANÁLISE DO CORPUS: MEMÓRIA DISCURSIVA E IDEOLOGIA NA PROPAGANDA POLÍTICA DE GRANDES EVENTOS ESPORTIVOS NO BRASIL CONTEMPORÂNEO}

É pela análise dos modos de relação das expressões dos textos, de seus implícitos e de suas retomadas ao nível da memória e do acontecimento que mostraremos adiante análises de SDs destacadas de anúncios de propagandas da Copa do Mundo de Futebol de 2014 e dos Jogos Olímpicos de 2016. Trata-se de analisar o jogo das contradições, numa dialética da diferença em que os conceitos acima apresentados serão retomados.Vejamos a SDR1:

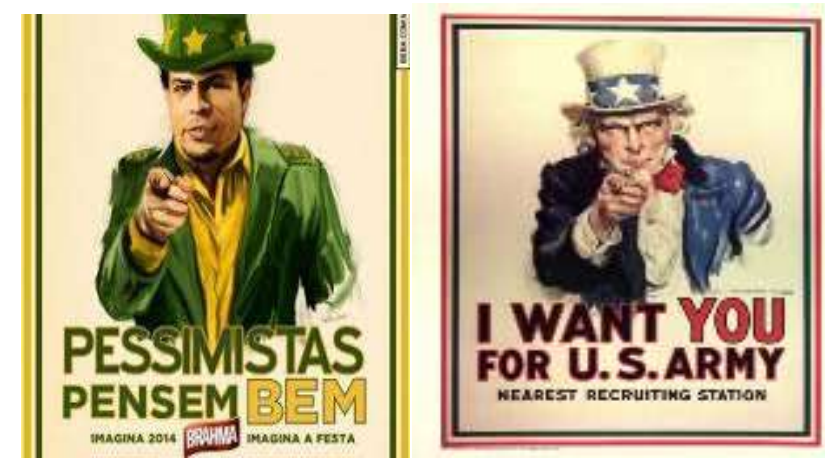

Figura 1: SD1: Pessimistas. Pensem bem. Imagina 2014. Brahma. Imagina a festa. Fonte: http://corazonada.com.br/blog/?tag=ronaldo. (acesso em 15/6/2014)

Nesta sequência, temos uma atualização do domínio de memória situado na convocatória norte-americana para a Segunda Grande Guerra. Portanto, o enunciado daquele acontecimento bélico deve ser resgatado.

Podemos tomar, portanto, o enunciado "I want you for U.S.Army. Nearest recrutation station" como sequência discursiva de referência (SDR1). Tal como propõe Serrani (1997), a SDR permite ao analista de discurso operar com os domínios de memória do jogo de sentido dos enunciados. Assim junto da SDR1, temos a SD1: "Pessimistas. Pensem bem. Imagina 2014. Brahma. Imagina a festa".

$\mathrm{Na}$ atualização deste domínio de memória, temos a propaganda de uma mercadoria (cerveja) no lugar da convocatória para a Guerra, cujo ícone é o dedo

\footnotetext{
${ }^{1}$ Tradução livre do autor: Eu quero você no Exército norte-americano. Na estação de recrutamento mais próxima”.
} 
apontado. No caso, temos uma convocatória para a Copa do Mundo de Futebol de 2014. A regularidade deste efeito de convocatória nos fez buscar a convocatória para a Segunda Grande Guerra, para, a partir desta regularidade, discutir o efeito de paráfrase em uma textualidade (cf. ORLANDI, 2001); uma regularidade que "não se deduz do corpus, ela é de natureza hipotética, ela constitui uma hipótese do analista (ACHARD, 1999, p. 14)".

É por este caminho que se desenha um modelo próprio para cada gesto de análise, provocando-se questões em pontos onde as confluências significativas de interpretação dos enunciados andam junto com o propósito ético de "dar voz" ao jogo político (MALDIDIER, 1997).

Como se pode notar, o efeito de sentido de convocatória sem escolha vem marcado pela oposição ao suposto pessimismo de parte da população em acreditar que algo não vai dar certo numa "festa", cujo efeito de sentido é de convocatória e que, por sua vez, por se tratar de recrutamento para uma Guerra aparece como ameaça, tal como se nota em "pensem bem". Este último trecho do enunciado sustenta um tom de ameaça e de expectativa marcado pelo medo, uma vez que antes de pensar com segurança caso se deseje mesmo torcer para que o evento não ocorra conforme os preparativos, o sujeito já foi convocado, de forma autoritária, antes, por um lugar "já lá", à sua revelia.

No caso, em meio às nossas hipóteses, tomadas como "dados" que indicam os sentidos dos indícios ao pesquisador (cf. TFOUNI, 1992), vemos como interpretar efeitos de sentido e mecanismos ideológicos mexe com os lugares "já lá" a que o sujeito intérprete estaria afixado, por uma rede de sentidos que assegura a universalidade dos enunciados posto que voltada ao sentido de unidade que apaga a alteridade do sujeito do discurso.

Nossa hipótese é a de que há um efeito autoritário no modo de lidar com a paráfrase, uma vez que o tom acusatório endereçado aos pessimistas. Este tom acusatório retoma "Imagina a festa", que, por sua vez, é sustentado pelo "Imagina na Copa", enunciado que ficou famoso por evocar possíveis falhas de infraestrutura nas obras para o evento. Este apelo se torna eficaz porque joga com as formações imaginárias, em que uma base material está disposta (PÊCHEUX, 1993). Trata-se de um apontamento acusatório em que implicitamente se mobiliza a autopercepção imaginária do brasileiro tal como "incapaz", "desordeiro", o que é assegurado por uma memória discursiva em que a ameaça do dedo apontado por uma autoridade do futebol legitima 
esses sentidos dominantes, e em contraste com o lema da bandeira nacional "Ordem e Progresso" (SDR2).

$\mathrm{Na}$ SD2, o jogo de cores da bandeira nacional também articula esse efeito de convocatória militar, que, alinha-se ao enunciado evocado pela SDR2 (imagem) e SD2. Como SDR2 temos o lema da bandeira nacional: "Ordem e progresso". Na parte verde da bandeira, lê-se a SD2, colocada no formato de uma legenda, a saber:

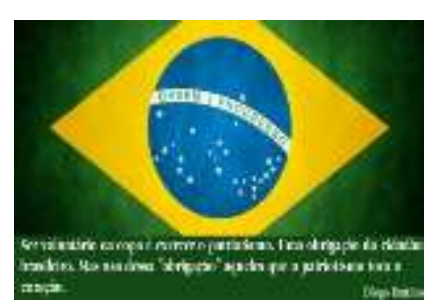

Figura 2: SD2: Ser voluntário na Copa é exercer o patriotismo. Uma obrigação do cidadão brasileiro. Mas usa dessa "obrigação" aqueles que o patriotismo toca o coração (Diogo Bottino).

Fonte: http://andradetalis.wordpress.com/2013/06/ (acesso em 15/8/2014)

Em ambos os casos, cabe indagar: quais efeitos de sentido esses domínios de memória sustentam? Sob quais naturalizações ideológicas? Em primeiro lugar, precisamos tratar da memória discursiva desses enunciados. É que ao tratar deste ponto fortalecemos uma linha de interpretação sobre o efeito encaixe que o pré-construído exerce sobre os enunciados por meio desse efeito de naturalização do "já lá" e do efeito de unidade, ambos regidos pela ideologia (cf. PÊCHEUX, 1993).

É esta linearidade que assegura um lugar dessas peças publicitárias. Como afirma Gomes (1998, p. 498):

no caso da produção de interpretações de realidade social, o que ocorre é que seus resultados são sempre "apropriados" de maneiras diversas por diferentes grupos sociais, o que os torna uma dimensão integrante e influente da própria realidade. Daí os vínculos nada diretos ou mecânicos, entre pensamento social e imaginário político.

Não podemos esquecer que esta maneira de veicular propaganda se situa no modo de produção capitalista. Neste, a produção de evidências racionalizadas por uma lógica tecnicista da produção em massa da informação calcula que para todos já há um lugar mais ou menos previsto por meio do qual se engole a informação, e em que um monopólio que esconde a falsa relação de identidade do universal e do particular torna 
possível ser reconhecido como alguém notável no cotidiano (ADORNO; HORKHEIMER, 1985).

Esse modo de fazer funcionar a propaganda de um evento lança mão de um efeito de crença na unidade, em que se apagam as diferenças e a alteridade vem a reboque da memória discursiva articulada às peças publicitárias. No caso, vemos ecoar pela memória discursiva o fortalecimento do aparelho tecnoburocrático que, conforme Gomes (1998) se intensificou com o governo de Vargas.

Em meio a isto, vemos uma colagem entre Estado e Nação daquele período de modo que a não valorização de partidos e assembleias pelas bases representativas alimentava a base técnica alinhada aos interesses dos governos e de sua governabilidade. Em meio às discrepâncias do jogo político dos governantes mandatários de um país ideal e a tentativa de abafar os conflitos do país real, Gomes (1998) destaca o fortalecimento de teorias políticas de Estado com esta feição, voltadas ao corporativismo e à propaganda. No ano de comemoração de 10 anos do governo Vargas, por exemplo, vê-se o cartaz: "Por ínfimo que seja no presente, o trabalho de cada brasileiro em bem da coletividade apressará o renovamento do futuro" (GOMES, 1998, p. 508).

Por conta disso, a aliança discursiva deste domínio de memória na SD2 é instigante. O sentido de prognóstico de futuro redentor, de união e força voltadas ao "bem comum" destaca o "ser voluntário" e o "patriotismo" e indica a força da vontade individual soberana às discordâncias. Vemos a sustentação de uma promessa de um patrimônio e um legado "para além" do sujeito-leitor.

As peças publicitárias que analisamos movimentam a memória discursiva, ao fazerem essas referências à época do governo Vargas, em que a difusão da propaganda política em larga escala materializa mecanismos ideológicos (BUSSETO, 2007).

Busseto (2007), por sua vez, mostra como o Estado Novo utilizou a Exposição de Televisão em 1939, em parceria com o III Reich alemão, intenso usuário da propaganda televisiva como controle autoritário, realizada pelo Departamento de Imprensa e Propaganda. $\mathrm{O}$ uso da televisão para a propaganda política andou aliada ao aquecimento de importações e exportações e, portanto, do consumo, ligado a eventos inclusive de caráter esportivo, como vemos na SD1, em que aparece uma marca de cerveja, no centro do enunciado.

Deste modo, refizemos os percursos destes ícones da atualidade aqui expressos pela convocatória à Copa do Mundo de Futebol de 2014 pelo domínio de memória do 
recrutamento ao exército norte-americano para a Grande Guerra na SD1, ou pelo apelo ao voluntariado e ao exercer uma "obrigação", na SD2, para apontar algumas direções dos efeitos de sentido pela via de um domínio de memória que sustenta o determinante político.

Trata-se de um efeito paradoxal da ideologia expresso em um chamado, um apelo que aposta na suposta liberdade individual do sujeito, mas joga com o sentido implícito de "obrigação" e de "recrutamento" em tom de ameaça ("Pensem bem").

No caso, temos assim uma relação do sujeito-leitor e do espectador num lugar de sujeito ideal em relação a um suposto saber de si, que, em AD é entendido como efeito de natureza ideológica sobre uma base semântica e desvela o acontecimento num domínio de memória. A respeito deste acontecimento velado por um retorno do dizer a si mesmo, "apagando" outros domínios de memória, que são construídos previamente, e insistem, podemos lembrar Achard (1999) quando diz:

a memória discursiva seria aquilo que, face a um texto que surge como acontecimento a ler, vem restabelecer os implícitos (quer dizer, mais tecnicamente, os pré-construídos, elementos citados e relatados, discursos-transversos, etc.) de que sua leitura necessita: a condição do legível ao próprio legível (ACHARD, 1999, p. 14).

A respeito desta última, a obviedade aliada à clareza de uma possível interpretação do enunciado decorre do pressuposto de que a regularidade da memória de que falávamos na seção anterior faz série com o legível ou desdobrar-se em paráfrases que desvelam uma nova série de regularidades (PECHEUX, 1999).

Nesta linha, podemos resgatar ainda o efeito de "Pense bem" na SD1, que, substitui o valor semântico de um patrimônio futuro equivalendo a prêmio por ter sido voluntário, e escondendo o sentido de atendimento pelo Estado de obras de infraestrutura de Direito do cidadão comum.

Em ambas as SDs, temos um efeito do regime de interpretação pautado no controle da deriva dos enunciados e em um apagamento da memória ratificado pela força de evidência semântica da ideologia. Há ainda um efeito do imaginário que apaga os desnivelamentos entre posição discursiva do sujeito-enunciador e interlocutores. Numa linha semelhante à analisada por Zoppi-Fontana (1997) acerca do papel do porta-voz no discurso político, temos uma identificação entre locutor e atos alocutários que definem eixos de regularidades e que se sustentam na figura do porta-voz rumo a uma simetria imaginária; é o que vemos em "todos estão convocados" 
Temos imagens acompanhadas de textos que significam a partir de um modo autoritário de controle da interpretação e do jogo com a memória discursiva e com os sentidos. Imagens que em meio a sua diagramação tentam disfarçar os equívocos e driblar questões interpretativas, naturalizando assim posições e crenças acerca de um evento $\mathrm{m}$ que supostamente "somos um só" (como aparece na propaganda televisiva da Rede Globo de televisão). Esses efeitos de sentido citados no parágrafo anterior são eficazes, porque mobilizam o campo das formações imaginárias sobre o que é (seria) ser brasileiro, organizar um evento. Trata-se de um mecanismo eficaz em que a ideologia interpela e convoca o sujeito a ocupar um lugar à espera (PÊCHEUX, 1993).

No caso, o interpretável vem de uma textualidade (ORLANDI, 2001) possível de ser resgatada pela memória discursiva (como vemos na SD1 sobre a convocatória para a Guerra) e marca de um acontecimento "todos estão convocados". Isto não faz aparecer que há somente uma paráfrase do enunciado que se refere à convocatória para uma guerra, mas as marcas linguísticas indicam um lugar delimitado ao sujeito, lugar de obediência e do qual não se escapa, uma vez que não se tem possibilidade de outra posição, na linha de um efeito paradoxal da ideologia.

O efeito de recrutamento de um voluntariado e de convocatória visto nas SDs acima também aparece em um anúncio dos jogos Olímpicos de 2016 que segue como SD4.

SD4 - Os heróis de quem se tornou atleta Olímpico aos 15 anos é um voluntário que vai atuar nos primeiros jogos que serão realizados na América do Sul. Seja o herói dos seus heróis. Seja voluntário dos jogos 2016. Inscreva-se no programa de voluntários dos Jogos olímpicos e Paralímpicos Rio 2016. Você vai receber treinamentos exclusivos, cursos de inglês online, conhecer diferentes culturas e ajudar na realização do maior evento esportivo do planeta. São diversas oportunidades e todo mundo pode participar. Faça parte do time Rio 2016. Inscrições: Rio2016.com/voluntários. Ou pelo telefone: 3004-2016.

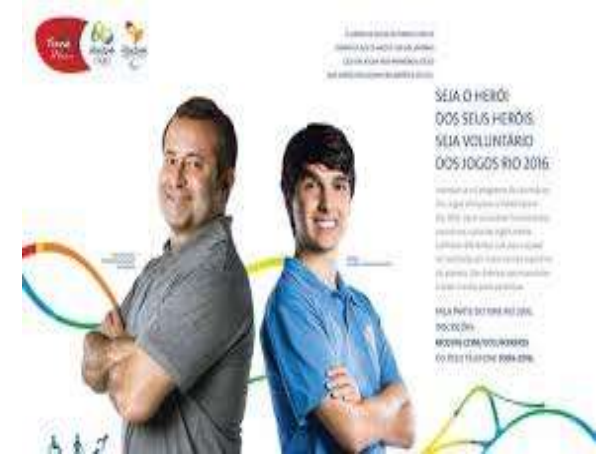

Figura 3: anúncio dos jogos Olímpicos de 2016 Fonte: https://www.google.com.br/search?q= voluntarios-rio- 
Chama a atenção na SD4 o efeito da nomeação em que o nome "herói" é tomado como referente para designar o voluntário como "herói dos heróis". Em seguida, temos o uso das formas verbais do imperativo "Seja" e "Inscreva-se". Do ponto de vista do imaginário, há um jogo de implícitos lançados para as imagens do filho e do pai; respectivamente o "herói voluntário" e o "herói dos seus heróis" sustentam um jogo de espelhamento acerca da ocupação dessas posições. A princípio, qualquer um pode ser "herói" e "herói dos heróis", de modo que qualquer um pode ser "voluntário dos jogos Rio 2016".

Do ponto de vista do efeito ideológico, temos o efeito de unidade em "todo mundo pode participar" que apaga as diferentes condições de possibilidade de participação inclusive marcada pelas diferenças de acesso a alguns dos pré-requisitos apresentados no próprio anúncio, a saber: faz-se necessário saber a língua inglesa.

Há um apagamento da base material da ideologia, pois para participar como voluntário demandaria o conhecimento da língua inglesa. Mesmo que seja oferecido o "curso de inglês online" não há garantia de que a participação se concretize. Vemos marcada uma contradição, pois "todo mundo" é segmentado pelo grupo "quem sabe ou não sabe inglês".

Além disso, temos uma substituição parafrástica de "herói" por "voluntário". sentido dominante de "herói" está atravessado pela vontade de se destacar; por outro lado, o sentido dominante de "voluntário" está atravessado pela atitude genuína, supostamente destituída de recompensa e troca. Deste modo, a migração de um termo como substituto do outro transita entre a paráfrase e a memória sem a ruptura com uma zona de sentido dominante.

Nessa SD4, a substituição de "herói" por "voluntário" ocorre de modo que o implícito cria o efeito de destaque, de caráter especial, em que a interpelação é feita sob o modo do efeito ideológico elementar a que se refere Pêcheux (1993). Trata-se conforme este autor do primeiro mérito althusseriano de mostrar que a ideologia funciona conforme o pressuposto de que somos sujeitos e de que ocupamos um lugar já marcado.

Esta mudança de zona de sentido também atrelada ao estatuto da memória discursiva pode ser assegurada, a partir da dupla via de acesso desta, entendida por Pêcheux (1999) contra o paradigma cognitivista da memória decodificadora, mas no 
enlace entre mito, dimensão sociohistorica e da dialética entre o legível e o que é possível de ler pela escansão de elementos implícitos, direta ou indiretamente marcados.

Esta sustentação da memória em um lugar supostamente mítico (em que nem começo, nem fim são marcados) é o que vemos na SD5 em que o anúncio das Olimpíadas, feito por uma marca de produtos esportivos que utiliza o enunciado "Eu já sabia" e em seguida desenvolve argumentos para convencer o consumidor sobre o fato de que o Brasil se transformará após o evento. Há um efeito imaginário de "já sabido", mesmo sem o evento ainda ter ocorrido. Segue:

SD5- Eu já sabia. Jogos Olimpícos Rio 2016. Mas não é por prever o futuro que a Olympikus já sabia. É porque aposta nele. Porque patrocina o Comitê Olímpico brasileiro desde 1999, quando trazer os jogos olímpicos para o Brasil era um sonho distante. E viu todo empenho do COB para fazer desse sonho realidade. Ano após ano. Sabia porque fez de todo o trabalho da candidatura brasileira a mais forte na disputa. Sabia porque patrocinou o Pan do Rio e ajudou a cidade a receber o maior evento esportivo da história do país e mostrar a todos que aquilo podia ser só o começo. E realmente era. $E$, depois que passarem os jogos olímpicos do Rio, depois que o Brasil fizer dessa festa um marco em sua história, fizer do esporte um instrumento de transformação e desse grande sonho realidade, a olympikus com certeza vai dizer novamente com todo orgulho: eu já sabia. (https://www.google.com.br/search?q=olimpiadas+2016+voluntarios\&biw=.ccsp.co m.br\%252Fultimas\%252Fnoticia.php\%253Fid\%253D42067\%3B960\%3B720. Acesso em 14/12/2014).

Chama a atenção, um efeito da memória discursiva sustentado pelo imaginário da transformação de um produto, tal como uma mercadoria. Além disso, vemos uma forma narrativa em "depois que passarem os jogos olímpicos do Rio" que ratifica esse uso do imaginário como se um produto transformado pela marca patrocinadora, uma vez ainda que a candidatura brasileira tornou-se a "mais forte".

Um dos efeitos de unidade no imaginário marcado pela ideologia aponta Pêcheux (1993), é este cuja herança vem do Empirismo Lógico, em que se acredita que se pode falar conforme o modelo "como se", o que ratifica a evidência de que $\mathrm{X}$ é $\mathrm{X}$.

De acordo com esta lógica dominante, o produto em questão ocupa o lugar de decifrar um lugar mítico da memória discursiva, uma origem impossível de ser definida, mas que mesmo assim aparece em: "podia ser só o começo. E realmente era (...) eu já sabia". Na sequência, o uso de "eu já sabia" ao final assegura o controle da interpretação e marca um lugar do imaginário em que se pode saber de algo de forma antecipada mesmo que isto seja impossível. 
Como se percebe, é evocado um efeito de pré-construído (PECHEUX, 1993, p. 105), um efeito de encaixe que alcança a "articulação de enunciados, implicação de propriedades, efeito de sustentação" e impõe a naturalidade de uma leitura única à realização do evento, mesmo que, como é sabido, circulem debates e manifestações populares em torno da polêmica dos investimentos financeiros do Estado para a realização do evento Copa do Mundo 2014.

Em suma, temos de modo geral um efeito de novidade em meio a enunciados cristalizados, mas baseado em formações imaginárias que, como vemos neste segundo recorte, ancoram-se em "velhos" clichês dos domínios de memória sobre política e futebol em nosso país.

Zoppi-Fontana (1997) explica que a inscrição do sujeito no político em que o lugar discursivo ocupado pela grande mídia autoriza uma transformação, lançada como promessa, mas que pela ideologia disfarça pistas pelas quais é possível resgatar parte do já dito (memória discursiva). Nos casos analisados o acontecimento discursivo "é apreendido na consistência de enunciados que se entrecruzam num momento dado" (GUILHAUMOU; MALDIDIER, 1997, p. 166) de modo que a análise "permite colocar em evidência as estratégias discursivas que se desenrolam no acontecimento" (idem, p. 181); deste modo, não é possível assegurar um evento futuro. Esta promessa, portanto, disfarça o caráter venatório por excelência da memória discursiva.

É por conta disso que interpretamos ecos da memória de ontem, "de fora", da propaganda política do exército norte-americano na Grande Guerra como efeito de textualização (ORLANDI, 2001), em que o sentido atribuído depende de uma evidência ideológica que the confere estabilidade semântica, pois supõe que os ocupantes ocupem lugares "já lá" (PECHEUX, 1997).

Para finalizar, vale ainda apontar um debate recente no campo da Análise de Discurso, que toca de alguma maneira os limites de nossa análise. Trata-se de considerar não apenas o campo das enunciações, da recepção e da circulação dos enunciados e os efeitos da memória; mas, sobretudo, indicar como um gesto analítico de interpretação como os que aqui foram apontados deslocam os mecanismos de naturalização semântica orquestrada pela ideologia.

Courtine (2006) contribui com esta discussão, ao tocar na complexidade do diálogo entre o determinante político e as condições de produção do enunciado. Afirma Courtine (2006, p. 64): 
O sujeito político, aquele que enuncia um discurso, está realmente assujeitado a um todo de muitas condições de produção e recepção de seu enunciado. Ele é o ponto de condensação entre linguagem e ideologia, o lugar onde os sistemas de conhecimento político se articulam na competência linguística, diferenciando-se um do outro, mesclando-se um ao outro, combinando com outro, ou afrontando-o em uma determinada conjuntura política.

Deste modo, este conjunto de peças publicitárias de eventos esportivos é regulada por evidências ideológicas que lhe conferem, a partir dos usos de alguns domínios de memória, um caminho de legibilidade e de efeito de textualização que desenham um espaço de interação entre locutor e ouvinte.

Portanto, temos um lugar de entremeio, em que a circulação da memória não se esgota em um ponto, mas se textualiza e cria efeitos de sentido em meio às imagens e aos textos analisados.

Sendo assim, os efeitos de sentido aqui apontados nessas peças publicitárias sustentam um apagamento do sujeito em deriva por meio da estabilidade semântica da ideologia fincada nos domínios de memória da "obrigação", do "ser voluntário", da "ordem" e da promessa de um futuro virtual.

\section{CONSIDERAÇÕES FINAIS}

Do ponto de vista da Análise de Discurso, ao ser formulada uma questão já se configura um inevitável gesto de interpretação político. É o que mostramos, ao mobilizar uma teoria sobre o caráter imaginário da base material da ideologia e suas estratégias de recrutamento, convocatória e efeito de unidade e de totalidade veiculado na propaganda de dois grandes eventos esportivos organizados no Brasil contemporâneo.

Trata-se de um processo discursivo de significação em que o sujeito aparece e é apagado na deriva dos enunciados e em sua alteridade por efeitos da ideologia pautados no recrutamento obrigatório, sustentado pelo efeito paradoxal da ideologia.

Temos, portanto, a sustentação na memória discursiva e pelo funcionamento da ideologia em que o recrutamento voluntário se mostra pelo disfarce da polissemia dos sentidos.

\section{REFERÊNCIAS}


ACHARD, P. Memória e produção discursiva do sentido. In.: P. ACHARD. (org.). O papel da memória. Campinas-SP: Pontes. 1999. 11-23.

ADORNO, T.; HORKHEIMER, M. A Indústria Cultural: o esclarecimento como mistificação das massas. In.: T. ADORNO; M. HORKHEIMER, M. Dialética do Esclarecimento: fragmentos filosóficos. Rio de Janeiro/RJ: Zahar. 1969/1985. 113-156.

AUTHIER-REVUZ, J. Palavras incertas: as não coincidências do dizer. Campinas/SP: Ed. da UNICAMP. 1998.

BUSSETO, A. Em busca da caixa mágica: o Estado Novo e a televisão. Revista Brasileira de História (Impresso), v. 27, p. 177-196, 2007.

COURTINE, J. J. Metamorfoses do discurso político: derivas da fala pública. São Carlos-SP: Claraluz editora. 2006.

COURTINE, J.J. Corpo, discurso, imagens: entrevistas. In.: J.J. COURTINE, J.J. Decifrar o corpo: pensar com Foucault. Petrópolis/RJ: Vozes, 2013. 11-46.

GINZBURG, C. Mitos, emblemas e sinais: morfologia e História. São Paulo/SP: Cia. Das Letras, 1989.

GOMES, A.C. A política brasileira em busca da modernidade: na fronteira entre o público e o privado. In.: SCHWARCS, L.M. (org.). História da Vida Privada no Brasil - vol. 4: contrastes da intimidade contemporânea. São Paulo-SP: Companhia das Letras. 1998. 489-558.

GUILHAUMOU, J.; MALDIDIER, D. Efeitos do arquivo: a AD no lado da História. In.: ORLANDI, E.P. et al. (org.). Gestos de leitura: da História no Discurso. Trad. B.S.C. MARIANI [et al]. 2a .ed. Campinas-SP: Ed. da UNICAMP. 1997. 163-189.

MALDIDIER, D. O discurso político e a guerra na Argélia. In.: ORLANDI, E.P. et al. (org.). Gestos de leitura: da História no Discurso. Trad. B.S.C. MARIANI [et al]. $2^{\mathrm{a}}$.ed. Campinas-SP: Ed. da UNICAMP. 1997. 145-163.

ORLANDI, E.P. A linguagem e seu funcionamento. Campinas/SP: Pontes. 1987.

ORLANDI, E.P. Discurso: fato, dado, exterioridade. In.: CASTRO, M.F.P. (org.). 0 método e o dado no estudo da linguagem. Campinas/SP. Ed. da UNICAMP, 1996, p. 209-219.

ORLANDI, E.P. Interpretação: autoria, leitura e efeitos do trabalho simbólico. Petrópolis/RJ: Vozes. 2001.

PÊCHEUX, M. Semântica e Discurso: uma crítica à afirmação do óbvio. Campinas/SP: UNICAMP, 1993.

PÊCHEUX, M Discurso: Estrutura ou acontecimento? Campinas: Pontes, 1997.

PÊCHEUX, M. Papel da memória. In.: ACHARD, P. (org.). O papel da memória. Campinas-SP: Pontes. 1983/1999. 49-59. 
SERRANI, S.M. Um método para estudar a discursividade na abordagem de questões socioculturais. In.: SERRANI, S. M. A linguagem na pesquisa sociocultural: um estudo da repetição na discursividade. Campinas/SP: ed. da UNICAMP. 1997. 53-71.

TFOUNI, L.V. O dado como indício e a contextualização do(a) pesquisador(a) nos estudos sobre compreensão da linguagem. DELTA, v. 8, n.2, SCT/PR, p.205-223, 1992a.

ZOPPI-FONTANA, M.G. Cidadãos modernos: discurso e representação política. Campinas/SP: Ed. da UNICAMP. 1997.

Artigo recebido em 25/08/2016

Artigo aceito em 22/12/2016 